\title{
A Study on Recognition and Demands of Forest Interpretation Programs: Focused on Jinju City and Gyeongnam Region
}

\author{
Nara Lee ${ }^{1,2}$, Keun Young Huh $^{2} *$, and Jonghoon Park ${ }^{3}$ \\ ${ }^{1}$ Div. of Natural Heritage, Natural Heritage Center, Daejeon 35204, South Korea \\ ${ }^{2}$ Dept. of Landscape Architecture, Gyeongnam National University of Science and Technology, Jinju 52725, South Korea \\ ${ }^{3}$ School of Planning, Design and Construction, Michigan State University, Michigan 48824, USA
}

\begin{abstract}
The purpose of this study was to investigate the recognition and demands of forest interpretation programs. Questionnaire survey was carried out to estimate the awareness, necessity, future participation intent, experience, satisfaction and demands of forest interpretation programs with 100 residents living in Jinju city or Gyeongnam region. The data were subject to frequency analysis, correlation analysis, and path analysis. Overall $63 \%$ of respondents didn't know forest interpretation programs, but $52 \%$ of respondents recognized the necessity of forest interpretation programs. $52 \%$ of respondents had the future participate intent of forest interpretation programs, and $38.3 \%$ didn't know if they would participate. $74 \%$ of respondents had never experienced the programs. In the satisfaction, $80 \%$ of respondents who experienced showed neutral. Future participation intent was highly correlated with necessity as shown in the result of correlation analysis among awareness, necessity, future participation intent, and experience of forest interpretation programs. Also future participation intent in path analysis was estimated to be affected indirectly by experience and awareness as well as necessity. Enhancement of future participation intent would be achieved by increasing experience, awareness, and necessity of forest interpretation programs. According to the demands, forest interpreters were required to have the expertise to provide knowledge and information of forests. Attractive content for forest interpretation programs was in the order of recreational activities $>$ forest conservation > education while the proper objective of forest interpretation programs was experience and interest $>$ education $>$ conservation and resource $>$ public relation of forests and parks. Respondents preferred participation and experience the most as a style in selecting the programs. Key condition in selecting the venue was diversity $>$ safety $>$ connectivity $>$ accessibility in order. There was no significantly different preference in proper participation duration or operation season for the activities of forest interpretation programs.
\end{abstract}

Keywords: awareness, experience, necessity, participation intent, path analysis

\section{Introduction}

Urban residents frequently visit national parks, natural recreation forests and mountains near the city for recreation. Moreover, the increasing environmental awareness has brought about greater interest in the importance of green space and nature restoration (Eom, 2008). These people's interest inevitably leads to understanding and education about forests. Therefore, the role of forest interpreters is expanding from merely guiding visitors through the forest to providing

This study is written based on the revision and improvement of the master's thesis of Gyeongnam National University of Science and Technology by Lee (2015) titled "A Study on Awareness and Demands of the Forest Interpretation Program".

Received: June 8, 2017, Revised: June 30, 2017, Accepted: July 18, 2017

*Comesponding author: sumoto@gntech.ac.kr 
understanding and education about forests itself and forest resources for the visitors.

The enactment of the Forestry Culture and Recreation Act in 2005 established the legal grounds for education and utilization of forest interpreters, and then the forest interpreter qualification system has been fully implemented through the Forest Education Promotion Act in 2012, resulting on approximately 6,500 interpreters trained as of December 2015 (Park and Jang, 2016). Furthermore, the number of participants in forest interpretation programs increased rapidly from 7 thousand in 1999 to 1.132 million in 2010 and then 1.806 million in 2014 (Korea Forest Service, 2015; Park and Jang, 2016).

Interpretation is an adequate combination of information, guidance and education services that help bring new understanding, insight and interest of users on cultural, historical and natural resources. At the same time it is a technique that describes the visiting place to visitors, having them recognize the importance of interrelation of the environment and realize the legitimacy of environmental conservation, and helps them to practice what they have learned in the forests (Cho, 2007; Edwards, 1965; Juvenvile et al., 1987). Forest interpretation provides a beautiful natural landscape for visitors while also helping them experience the forest as well (Jeoun et al., 2014).

Up until recently, the studies on forest interpretation have been on the participation motive and job training satisfaction of forest interpreters or the demands and development of forest interpretation programs (Cho, 2007, 2012; Jeoun et al., 2014; Ko and Shin, 2011; Park and Jang, 2016), but this research area is still at a level where many research results have not been derived. In particular, the major results among the studies that have been conducted thus far on development of forest interpretation programs were derived by Cho (2007, 2012), who conducted researches on the characteristics of visitors in Woraksan National Park and Baekunsan Natural Recreation Forest. In fact, forest interpretation programs have been developed and implemented empirically by forest interpreters assigned in different recreational forests, without systematic evaluation or feedback about the programs. Therefore, this study was conducted to determine the public awareness, necessity, future participation intent, experience and satisfaction, and demands of forest interpretation programs, and suggest programs to increase future participation intent and satisfaction through the results.

\section{Research Method}

This study set the hypothesis that there are key factors to increase public participation and satisfaction in forest interpretation programs and that they are correlated to one another, and designed an experiment for verification. Accordingly, the recognition and demands of participants on forest interpretation programs were analyzed, and their attitude toward the programs of potential users was also evaluated. The experimental design consists of questionnaire design, survey and statistical analysis. Total 107 survey participants were selected by random sampling once they agreed to participate after the researchers personally explained the survey objective and method in Jinju and Gyeongnam region where arboretums and recreational forests are located nearby (Kim et al., 2009). Total 100 questionnaires were selected, excluding those with insincere or insufficient responses, among the ones finally collected. The questionnaire design consists of three categories according to the conceptual definition and variables as shown in Table 1. First, there are 4 variables on socio-demographic background as general characteristics. Second, there are 5 variables on the recognition of potential users of forest interpretation: each rated on a 5-point Likert scale; for example, the question for "awareness of forest interpretation programs" was" How much do you think you know about forest interpreters or forest interpretation programs?", which was rated 5 points for "very well" and 1 point for "not at all" (Kim et al., 2009). Third, there were 9 variables on demands of respondents as potential users on forest interpretation program. The collected data was analyzed using IBM SPSS ver. 24.0, conducting a frequency analysis on recognition and demands of forest interpretation programs 
Table 1. Scheme of questionnaire design.

\begin{tabular}{|c|c|c|}
\hline Category & Variable & No. of questions \\
\hline Socio-demographic background & Sex, age, education, residence area & 4 \\
\hline \multirow{5}{*}{$\begin{array}{l}\text { Recognition of forest interpretation } \\
\text { programs }\end{array}$} & Awareness of forest interpretation program & \multirow{5}{*}{5} \\
\hline & Necessity of forest interpretation program & \\
\hline & Future participation intent of forest interpretation program & \\
\hline & Experience of forest interpretation program & \\
\hline & Satisfaction of forest interpretation program & \\
\hline \multirow{9}{*}{$\begin{array}{l}\text { Demands related to forest interpreter } \\
\text { and interpretation programs }\end{array}$} & Proper major of forest interpreter & \multirow{9}{*}{9} \\
\hline & Appropriate education level of forest interpreter & \\
\hline & Appropriate career of forest interpreter & \\
\hline & Attractive content for forest interpretation programs & \\
\hline & Proper objective of forest interpretation programs & \\
\hline & Preferable style in selecting forest interpretation programs & \\
\hline & Key condition in selecting the venue for forest interpretation program & \\
\hline & Proper participation duration of forest interpretation programs & \\
\hline & Proper operation season for forest interpretation programs & \\
\hline
\end{tabular}

as well as socio-demographic background of participants. Exploratory correlation analysis and path analysis were conducted on the variables to determine the correlation among awareness of forest interpretation programs, necessity, future participation intent, and experience.

\section{Results and Discussions}

\section{Socio-demographic background}

Of all respondents, $68 \%$ were male and $32 \%$ were female, showing that there were relatively more male respondents than female. $75 \%$ of them were in their 20 s, followed by $17 \%$ in their $30 \mathrm{~s}, 5 \%$ under age $18,2 \%$ in their $50 \mathrm{~s}$, and $1 \%$ in other ages, indicating that the youth and the prime-aged population have interest in forest interpretation (Table 2). They were relatively younger than the major age groups visiting recreational forests and mountains in the suburbs (Kim and Huh, 2016; Heo et al., 2016). As for education level, undergraduate students and bachelor degree holders accounted for $38 \%$ and $22 \%$, while others took up $39 \%$, showing an even distribution. For residential area, Jinju took up $72 \%$ and Gyeongnam region $27 \%$.

\section{Recognition on forest interpretation programs}

The result of analyzing the awareness of forest interpretation programs showed that $32 \%$ of the respondents said they do not know it well, and $31 \%$ said they have never heard of it, indicating that overall, $63 \%$ are not sufficiently aware of forest interpretation programs (Table 3). In a study on the user characteristics of recreational forests in the suburbs and the promotion of recognition in forest recreation culture, Lee and Kim (2001) discovered that user awareness of forest culture programs was not very high. Park et al. (2002) claimed in a study on the user behavior of recreational forests that the 
Table 2. Socio-demographic background of respondents.

\begin{tabular}{|c|c|c|}
\hline & & Percent (\%) \\
\hline \multirow{3}{*}{ Gender } & Male & 68 \\
\hline & Female & 32 \\
\hline & Total & 100 \\
\hline \multirow{6}{*}{ Age } & 18 and under & 5 \\
\hline & $19-29$ & 75 \\
\hline & $30-39$ & 17 \\
\hline & $40-60$ & 2 \\
\hline & $60+$ & 1 \\
\hline & Total & 100 \\
\hline \multirow{5}{*}{ Education } & High school and others & 39 \\
\hline & Undergraduate & 38 \\
\hline & Bachelor degree & 22 \\
\hline & Master degree and higher & 1 \\
\hline & Total & 100 \\
\hline \multirow{4}{*}{ Residential location } & Jinju city & 72 \\
\hline & Gyeognam province $^{\mathrm{z}}$ & 27 \\
\hline & Other & 1 \\
\hline & Total & 100 \\
\hline
\end{tabular}

${ }^{\mathrm{z}}$ There Jinju city was excluded though it was a part of Gyeognam province.

Table 3. Awareness, necessity, and future participation intent of forest interpreter and interpretation program.

\begin{tabular}{|c|c|c|}
\hline \multicolumn{2}{|c|}{ Variable } & \multirow{2}{*}{$\frac{\text { Percent }(\%)}{5}$} \\
\hline \multirow{6}{*}{ Awareness of forest interpretation program } & Know it very well & \\
\hline & Know it well & 5 \\
\hline & Moderate & 27 \\
\hline & Don't know it well & 32 \\
\hline & Never heard of it & 31 \\
\hline & Total & 100 \\
\hline \multirow{6}{*}{$\begin{array}{l}\text { Necessity of forest interpreter and } \\
\text { interpretation program }\end{array}$} & Strongly necessary & 7 \\
\hline & Necessary & 45 \\
\hline & Neutral & 39 \\
\hline & Unnecessary & 8 \\
\hline & Strongly unnecessary & 1 \\
\hline & Total & 100 \\
\hline \multirow{6}{*}{$\begin{array}{l}\text { Future participation intent of forest } \\
\text { interpretation program }\end{array}$} & Definitely would & 10 \\
\hline & Would & 52 \\
\hline & Might & 38 \\
\hline & Wouldn't & 0 \\
\hline & Definitely wouldn't & 0 \\
\hline & Total & 100 \\
\hline
\end{tabular}


awareness of forest interpretation programs was low at 11\%. Even though the awareness of forest interpretation programs in this study is low at 27\%, it shows an increase compared to the results by Lee and Kim (2001) and Park et al. (2002). The result of analyzing the necessity of forest interpreters and forest interpretation programs showed that $7 \%$ of the respondents said they are strongly necessary, $45 \%$ said they are necessary, and 39\% gave a neutral response, proving that overall the recognition on the necessity was obviously high. In a study on the plans to promote National Recreation Forest, Kim et al. (2007) claimed that users recognize the importance of managing education and outdoor learning programs. The result of analyzing future participation intent of forest interpretation programs showed that $52 \%$ of the respondents said they would participate, and 38\% said they might. Park et al. (2002) claimed that $63.4 \%$ responded they would participate in forest interpretation programs if possible. Overall the awareness of forest interpretation programs was low, but the necessity and participation intent were relatively high. To increase practical participation, it is necessary to come up with a way to attract active participation of people who say that they would or might participate.

The result of analyzing the experience of forest interpretation programs showed that the highest ratio (74\%) of the respondents said they never experienced, followed by $11 \%$ that experienced once and $4 \%$ that experienced at least 10 times (Table 4). In the analysis of satisfaction among the respondents that have experience in forest interpretation programs, $80 \%$ said they were neutral, followed by $8 \%$ that were strongly satisfied and $8 \%$ that were satisfied, $4 \%$ that were strongly unsatisfied and $0 \%$ that were unsatisfied. Park et al. (2002) claimed that the biggest motive for visiting recreational forests is clear water and valley, followed by rest and meditation, stress relief, breakaway from the city, and appreciation of natural landscape. Connell and Meyer (2004) mentioned that people visit botanical gardens to enjoy themselves, appreciate the landscape, have quality time with friends or family, and find pleasure in staying within nature. Ballantyne et al. (2008) discovered that the visitors'motivations of interest, concentration, and education on conservation were relatively low at Mt. Coot-tha Botanic Gardens in Australia. Considering these results, the visitors' expectations and demands of forest interpretation programs may not be limited only to education. Therefore, it is necessary to determine the factors that affect satisfaction and improve satisfaction by interpreting the correlation and influence among factors though most showed at least a neutral level of satisfaction or higher.

Table 4. Experience and satisfaction of forest interpretation program.

\begin{tabular}{|c|c|c|}
\hline \multicolumn{2}{|c|}{ Variable } & \multirow{2}{*}{$\begin{array}{c}\text { Percent (\%) } \\
4\end{array}$} \\
\hline \multirow{6}{*}{$\begin{array}{l}\text { Experiences of forest interpretation program } \\
\text { (times) }\end{array}$} & More than 10 & \\
\hline & $5-9$ & 2 \\
\hline & $2-4$ & 9 \\
\hline & One & 11 \\
\hline & Never & 74 \\
\hline & Total & 100 \\
\hline \multirow{6}{*}{$\begin{array}{l}\text { Satisfaction of forest interpretation program } \\
\text { (if participated) }\end{array}$} & Strongly satisfied & 8 \\
\hline & Satisfied & 8 \\
\hline & Neutral & 80 \\
\hline & Unsatisfied & 0 \\
\hline & Strongly unsatisfied & 4 \\
\hline & Total & 100 \\
\hline
\end{tabular}


As a result of analyzing the correlation among awareness, necessity, future participation intent and experience of forest interpretation programs to promote participation, it was found that future participation intent had a significant correlation with necessity, awareness with necessity and experience, necessity with awareness and future participation intent, and experience with awareness $(p<.01)$.

The model in Fig. 1 is obtained from the result of path analysis using an exploratory method among forest interpretation programs awareness, necessity, future participation intent and experience with correlation. Although theoretical interpretation is limited because the model was derived with an exploratory method without the basis on previous research findings, the model can be interpreted as follows. The model was fit with chi-square $\left(\chi^{2}\right)$ statistics at 2.813 , degree of freedom (df) 3, and p .421. Furthermore, according to Kim (2010), Xu and Fox (2014), Kim and Huh (2016), GFI (goodness of fit index) was 1.000 while .90 or higher is the adequate level, and RMR (root mean square residual) was .032 while .050 or lower is the adequate level. AGFI (adjusted GFI) was 0.953 while .900 or higher is adequate, NFI (normal fit index) was 0.954 while 0.900 or higher is adequate, and TLI (Tucker-Lewis index) was 1.007 while 0.9 or higher is adequate. As a result, the model's goodness of fit turned out to be satisfactory.

The non-standardized and standardized regression coefficients between [awareness $\leftarrow$ participation experience] are .459 and .428 , respectively, and $p$ was .000, indicating great significance (Table 6). And then [necessity $\longleftarrow$ awareness] and [future participation intent $\leftarrow$ necessity] were also highly significant. The statistical significance of indirect effect was

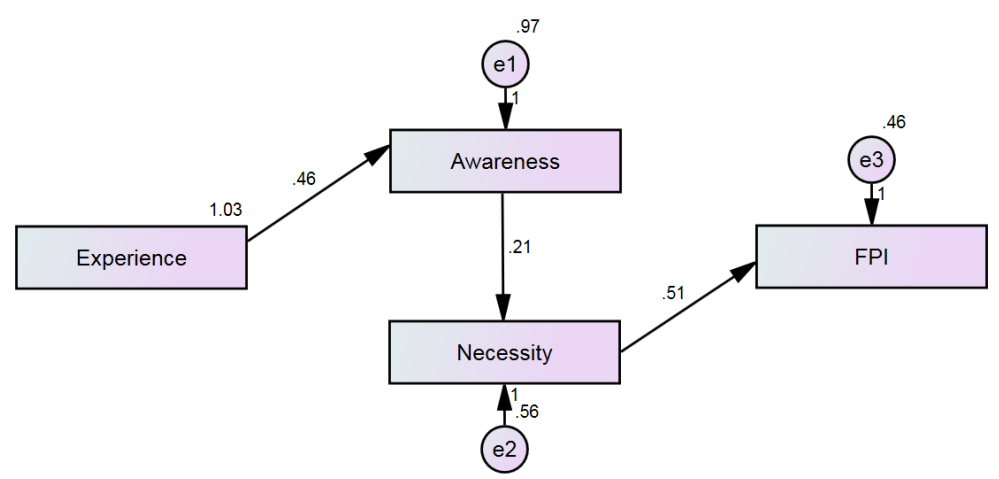

Figure 1. Path analysis model of awareness, necessity, future participation intent (FPI), and experience of forest interpretation program: $\chi^{2}=2.813, \mathrm{df}=3, p=.421$.

Table 5. Correlation of awareness, necessity, future participation intent, and experience of forest interpretation program.

\begin{tabular}{|c|c|c|c|c|c|}
\hline & Variable & Awareness & Necessity & $\mathrm{FPI}^{\mathrm{z}}$ & Experience \\
\hline \multirow{2}{*}{ Awareness } & Person correlation & 1.000 & & & \\
\hline & Sig. (2-tail) & & & & \\
\hline \multirow{2}{*}{ Necessity } & Person correlation & $.291^{* *}$ & 1.000 & & \\
\hline & Sig. (2-tail) & .003 & & & \\
\hline \multirow{2}{*}{ FPI } & Person correlation & .193 & $.505^{* *}$ & 1.000 & \\
\hline & Sig. (2-tail) & .054 & .000 & & \\
\hline \multirow{2}{*}{ Experience } & Person correlation & $.428 * *$ & .013 & .099 & 1.000 \\
\hline & Sig. (2-tail) & .000 & .900 & .328 & \\
\hline
\end{tabular}

${ }^{\mathrm{z}}$ Future participation intent

** Correlation is significant at the 0.01 level (2-tailed). 
Table 6. Regression weights among awareness, necessity, future participation intent, and experience of forest interpretation program.

\begin{tabular}{lccccc}
\hline & Unstandardized estimate & Standardized estimate & S.E. & C.R. & $p$-value \\
\hline Awareness $\leftarrow$ Experience & .459 & .428 & .097 & 4.711 & .000 \\
Necessity $\leftarrow$ Awareness & .208 & .291 & .069 & 3.021 & .003 \\
FPI $^{2} \leftarrow$ Necessity & .510 & .505 & .088 & 5.819 & .000 \\
\hline
\end{tabular}

${ }^{\mathrm{z}}$ Future participation intent; S.E.: standarded error; C.R.: critical ratio

Table 7. Standardized indirect effects and two tailed significance among of awareness, necessity, future participation intent, and experience of forest interpretation program.

\begin{tabular}{|c|c|c|c|c|}
\hline & & Experience & Awareness & Necessity \\
\hline \multirow{2}{*}{ Awareness } & Standardized indirect effect & .000 & .000 & .000 \\
\hline & $p$-value & - & - & - \\
\hline \multirow{2}{*}{ Necessity } & Standardized indirect effect & $.124^{*}$ & .000 & .000 \\
\hline & Sig. (2-tail) & .010 & - & - \\
\hline \multirow{2}{*}{$\mathrm{FPI}^{\mathrm{z}}$} & Standardized indirect effect & $.063^{*}$ & $.505^{*}$ & .000 \\
\hline & Sig. (2-tail) & .010 & .010 & - \\
\hline
\end{tabular}

${ }^{\mathrm{z}}$ Future participation intent

* Indirect effect is significant at the 0.05 level (2-tailed).

tested with bootstrapping (Kim, 2010), and the result showed that the standardized indirect effect of [participation experience $\rightarrow$ awareness $\rightarrow$ necessity] is .124 and $p .010$, showing significance (Table 7). The indirect effect of [participation experience $\rightarrow$ awareness $\rightarrow$ necessity $\rightarrow$ future participation intent] and [awareness $\rightarrow$ necessity $\rightarrow$ future participation intent] also turned out to be significant. Therefore, this indicates that participation experience of forest interpretation programs has direct and indirect positive effects with significance on awareness, necessity, and future participation intent, and awareness on necessity and future participation intent. Moreover, necessity has direct positive effects with significance on future participation intent.

\section{Demands of forest interpretation programs}

\section{Forest interpreters}

The most proper major for forest interpreter was forestry, landscape architecture and horticulture that took up 91\%, implying that having expertise is important (Table 8). The appropriate education level of forest interpreter was bachelor degree (45\%), while 35\% also said it doesn't matter, which shows that while it is good to have specialized knowledge, a similar level of people also thinks it doesn't matter. The appropriate career of forest interpreters was providing knowledge and information of forests (46\%), followed by communicating with participants (27\%) and minimizing use of forest resources (19\%). With regard to this, Ha and Kim (2006) presented 6 categories as the major tasks of forest interpreters: developing expertise, understanding the target area, program planning, development, implementation and evaluation. Cho (2007) mentioned that natural environment interpretation is a tool that provides inspiration, education, culture and beautiful recreational experience for visitors of national parks and natural recreation forests, and conserves the culture, 
Table 8. Demands of respondents as latent user related to major, education level, and career of forest interpreter.

\begin{tabular}{|c|c|c|}
\hline & Variable & Percent $(\%)$ \\
\hline \multirow{6}{*}{ Proper major of forest interpreter } & Education & 4 \\
\hline & Arts & 0 \\
\hline & Humanities & 3 \\
\hline & Forestry, landscape Architecture, horticulture & 91 \\
\hline & Other & 2 \\
\hline & Total & 100 \\
\hline \multirow{6}{*}{ Appropriate education level of forest interpreter } & High school & 5 \\
\hline & College graduate & 9 \\
\hline & Bachelor degree & 45 \\
\hline & Master degree and higher & 6 \\
\hline & Does't matter & 35 \\
\hline & Total & 100 \\
\hline \multirow{6}{*}{ Appropriate career of forest interpreter } & Providing knowledge and information of forests & 46 \\
\hline & Communicating with participants & 27 \\
\hline & Minimizing uses of forest resources & 19 \\
\hline & Implementing public relation of forest organizations and programs & 7 \\
\hline & Other & 1 \\
\hline & Total & 100 \\
\hline
\end{tabular}

history and natural resources for the agencies that manage the national parks and natural recreation forests. Overall forest interpreters need the education level and career to provide knowledge and necessary information on forests for visitors, and to minimize the use of forest resources for management agencies.

\section{Forest interpretation programs}

In the demand of attractive contents for forest interpretation programs, recreational activities accounted for the highest ratio at 47\%, followed by forest conservation (32\%) and education (12\%) (Table 9). Park et al. (2002) mentioned that people showed most interest in environmental conservation for the contents that must be included in forest interpretation programs, followed by forest functions, trees and flowering plants, and wild animals, while this study proved that people generally showed interest in recreation and environmental conservation. Proper objective of forest interpretation programs were experience and interest at the ratio of $42 \%$, followed by education (20\%), conservation and resource, and public relation of forests and parks (19\%). The preferable style in selecting forest interpretation programs was participation and experience with the highest ratio of $52 \%$, followed by recognizing the importance of how to use and conserve forests (31\%). This is similar to the above-mentioned results by Park et al. (2002), Connell and Meyer (2004), and Ballantyne et al. (2008), indicating that users prefer amusing programs for recreational activities while showing relatively lower preference in educational programs.

The key condition in selecting the venue for forest interpretation programs was diversity with the highest ratio of $45 \%$, followed by safety (20\%), connectivity to the community (19\%), and accessibility (15\%) (Table 10). Kim et al. (2007) 
Table 9. Demands of respondents as latent user related to content, purpose, and style of forest interpretation programs.

\begin{tabular}{|c|c|c|}
\hline \multicolumn{2}{|c|}{ Variable } & \multirow{2}{*}{$\frac{\text { Percent }(\%)}{12}$} \\
\hline \multirow{6}{*}{ Attractive content for forest interpretation programs } & Education & \\
\hline & Recreational activities & 47 \\
\hline & Forest conservation & 32 \\
\hline & Public relation of forests and parks & 8 \\
\hline & Other & 1 \\
\hline & Total & 100 \\
\hline \multirow{6}{*}{ Proper objective of forest interpretation programs } & Eduction & 20 \\
\hline & Experience and interest & 42 \\
\hline & Conservation and resource & 19 \\
\hline & Public relation of forests and parks & 19 \\
\hline & Other & 0 \\
\hline & Total & 100 \\
\hline \multirow{6}{*}{ Preferable style in selecting forest interpretation programs } & Knowledge delivery & 11 \\
\hline & Participation and experience & 52 \\
\hline & How to use and conserve forests & 31 \\
\hline & Promotion to understand forests more & 5 \\
\hline & Other & 1 \\
\hline & Total & 100 \\
\hline
\end{tabular}

Table 10. Demands of respondents as latent user related to condition, participation duration, and operation season of forest interpretation programs.

\begin{tabular}{|c|c|c|}
\hline \multicolumn{2}{|c|}{ Variable } & \multirow{2}{*}{$\frac{\text { Percent }(\%)}{15}$} \\
\hline \multirow{6}{*}{$\begin{array}{l}\text { Key condition in selecting the venue for forest } \\
\text { interpretation program }\end{array}$} & Accessibility & \\
\hline & Safety & 20 \\
\hline & Diversity & 45 \\
\hline & Connectivity to the community & 19 \\
\hline & Etc & 1 \\
\hline & Total & 100 \\
\hline \multirow{6}{*}{$\begin{array}{l}\text { Proper participation duration of forest interpretation } \\
\text { programs }\end{array}$} & One day experience type & 22 \\
\hline & Short term experience type & 27 \\
\hline & Long term experience type & 20 \\
\hline & Regular experience type & 30 \\
\hline & Other & 1 \\
\hline & Total & 100 \\
\hline \multirow{6}{*}{$\begin{array}{l}\text { Proper operation season for forest interpretation } \\
\text { programs }\end{array}$} & Spring & 33 \\
\hline & Summer & 19 \\
\hline & Fall & 15 \\
\hline & Winter & 4 \\
\hline & Does't matter & 29 \\
\hline & Total & 100 \\
\hline
\end{tabular}


mentioned in a study on the activation of National Recreation Forest that users recognize high importance of 'management of education and outdoor learning programs', 'various experience programs', and 'tour packages connected to surroundings' and that it is necessary to prepare various education and experience programs, and tour packages accordingly. The study showed a similar tendency in terms of diversity of venues and connectivity to the community. The proper participation duration of forest interpretation programs showed similar percentages overall. Regular experience type was highest at $30 \%$, but the others were also similar, such as short-term experience type at $27 \%$, one-day experience type $22 \%$, and long-term experience type $20 \%$. The proper operation season for forest interpretation programs was spring (33\%), followed by summer (19\%) and fall (15\%), while $4 \%$ also said winter and $29 \%$ said it doesn't matter. It seemed that forest interpretation programs can be operated regardless of the season unless the climatic conditions make outdoor activities impossible.

\section{Conclusion}

This study was conducted to analyze the recognition and demands of forest interpretation programs for wise use and improvement of forest recreational resources. To estimate the awareness, necessity, future participation intent, experience and satisfaction, and demands of forest interpretation programs, a survey was conducted on 100 residents living in Jinju city or Gyeongnam region. Frequency analysis, correlation analysis and path analysis were conducted on the collected data. Overall $63 \%$ of the respondents were not sufficiently aware of forest interpretation programs, while the recognition on the need of such programs was obviously high. The analysis of future participation intent of forest interpretation programs showed that $52 \%$ said they would participate, and $38 \%$ said they might. $74 \%$ responded that they had never experienced forest interpretation programs, and $80 \%$ of those with experience responded they were neutral about their satisfaction with the programs. The correlation analysis among the awareness, necessity, future participation intent and experience of forest interpretation programs showed that future participation intent had a highly significant correlation with necessity. In the path analysis, it was found that not only necessity but also awareness and experience had an indirect positive effect on future participation intent. Therefore, future participation intent can be improved by increasing experience and awareness as well as necessity. Forest interpreters needed expertise to provide knowledge and necessary information on the forests. The attractive contents for forest interpretation programs was recreational activities, followed by forest conservation and education. The proper objective was experience and interest, followed by education, conservation and resource, and public relation of forests and parks. The preferable style in selecting forest interpretation programs was participation and experience, and the key condition in selecting the venue was diversity, followed by safety, connectivity and accessibility. The participation duration and season for forest interpretation programs did not show any distinctive features.

\section{References}

Ballantyne, R., J. Packer, and K. Hughes. 2008. Environmental awareness, interests and motives of botanic gardens visitors: implications for interpretive practice. Tour. Manag. 29(3):439-444. DOI: :10.1016/j.tourman.2007.05.006

Cho, K.J. 2007. A study of visitor characteristics for development of interpretative program for the park: Case study of Woraksan national park. J. Korean Inst. For. Recreat. 11(2):1-9.

Cho, K.J. 2012. A study of visitor characteristics for development of forest interpretative program for the Bakun-san recreation forest: Case study of Baekunsan national park. J. Kor. Inst. For. Recreation 16(1):93-101. 
Connell, J. and D. Meyer. 2004. Modelling the visitor experience in the gardens of Great Britain. Curr. Issues Tour. 7(3):183-216. DOI: $10.1080 / 13683500408667979$

Edwards, R.Y. 1965. Park interpretation. Park News 1(1):11-16.

Eom, S.K. 2008. Study on appraisal of urban open space based on usability: With emphasis new metropolitan towns. $\mathrm{PhD}$ Diss., University of Seoul, Seoul, Korea.

Ha, S.Y. and I.H. Kim. 2006. Job analysis of the forest interpreters based on the DACUM method. Environ. Educ. 19(3):57-66.

Heo, H., I. Kim, E.J. Jo, K.Y. Huh, and J. Park. 2016. Analysis on residents recognition and preference for planning a natural recreation forest near city: Focused on planning Mt. Wora natural recreation forest in Jinju city. J. Korean Soc. People Plants Environ. 19(6):639-647. DOI: 10.11628/ksppe.2016.19.6.639

Jeoun, B.G., H.G. Jung, J.G. Jang, and J.H. Lee. 2014. Study on characteristics and job satisfaction of forest interpreters in Daegu and Gyeongbuk Regions. J. Korean Inst. For. Recreat. 18(3):11-19.

Juvenville, A., B.W. Twight, and R.H. Becker. 1987. Outdoor recreation management: theory and application. Venture Publishing, Inc., Pennsylvania, USA.

Kim, C.W., H.J. Yoon, and T.S. Lee. 2007. A study on the activation of national recreation forest: using importanceperformance analysis-. Tour. Stud. 21(4):101-119.

Kim, I., H.C. Heo, and K.Y. Huh. 2009. Evaluating user's behavior and satisfaction on pop-jet fountain of Namgaram park in Jinju. J. Korean Soc. People Plants Environ. 12(3):53-67.

Kim, J.M. and K.Y. Huh. 2016. Structure model analysis on visitors satisfaction of sightseeing in Mt. Keumwon arboretum. J. Korean Soc. People Plants Environ. 19(3):261-268. DOI: 10.11628/ksppe.2016.19.3.261

Kim, K.S. 2010. Amos 18.0 Structural equation model analysis. 1st ed. Hannarae Publishing Co., Seoul, Korea.

Ko, D.H. and W.S. Shin. 2011. Forest interpreter's satisfaction and needs of job competency education. J. Korean Inst. For. Recreat. 15(3):61-70.

Korea Forest Service. 2015. Statistical yearbook of forestry 2015. 45(VII):363.

Lee, J.L. and S.Y. Kim. 2001. A study on patterns in use of visitors to recreational forests near cities and their awareness of recreation culture in forest. J. Korean Inst. For. Recreat. 5(3):19-26.

Park, M.S., K.W. An, K.S. Jeon, and J.M. Park. 2002. The current usage of recreation forests under the western national forest office. J. Korean Inst. For. Recreat. 6(3):87-94.

Park, S.H. and I.Y. Jang. 2016. The effect of the forest interpreters'volunteering motivation and contents on voluntary activity satisfaction. J. Korean Inst. For. Recreat. 20(1):57-67.

Xu, F. and D. Fox. 2014. Modelling attitudes to nature, tourism and sustainable development in national parks: a survey of visitors in China and the UK. Tour. Manag. 45:142-158. DOI: 10.1016/j.tourman.2014.03.005 